\title{
Attention as Bounded Resource and Medium in Cultural \\ Memory - a Phenomenological or Economic Approach?
}

\author{
Jörg Bernardy \\ Institute of Philosophy \\ University of Hildesheim \\ bernardy@uni-hildesheim.de
}

\begin{abstract}
What is the role of attention in the dialectics of memory and communication? In how far is attention functioning as a medium? Which role does attention play in the information management practices? Attention is not only fundamental to human existence but also to the process of understanding. If understanding is mediated by memory (tradition) and communication (dialogue) then attention can be identified with the medium. So whenever you search to explain the role and mecanisms of memory in the information society, the question of attention is asked immediately. Furthermore, attention can be analysed under the following topics: as cognitive process, as subjevtive, intersubjective and cultural phenomenon and as resource and medium within an 'Attention Economy'. Whereas the first aspect has to be seen in the context of empirical studies in psychology and cognitive sciences, the phenomenological, cultural and economic aspects seem to have common points and similar implications in their theoretical approaches. In the last 20 years, the notion of attention has been the central core of several discourses in German phenomenology (Bernhard Waldenfels 2004), economy (Georg Franck 1998) and cultural studies (Aleida Assmann 2001). Similar to Georg Francks theory of mental capitalism, the idea of an attention economy also was followed up in the American disourse (e.g. Goldhaber, Davenport, Lanham). This article is supposed to explore the role of attention and its function as a medium within communication, cultural memory and science.
\end{abstract}

Author Biography

Jörg Bernardy is Doctoral Researcher and teaches Philosophy at the University of Hildesheim. He studied Philosophy and Romance Studies in Cologne, Düsseldorf and Paris. His current research interests include the literary forms of Philosophy, the works of Foucault and Schopenhauer, and the phenomenology of linguistic experience. 


\section{Introduction}

In this article I will neither answer the question of what attention is nor will I say or try to find out which approach is the best. Nevertheless I am confronted with the defiance how to define attention. It is in the first volume of the Principles of Psychology that William James gives the first famous definition which you also can find on Wikipedia today:

Everyone knows what attention is. It is the taking possession by the mind, in clear and vivid form, of one out of what seem several simultaneously possible objects or trains of thought. Focalization, concentration, of consciousness are of its essence. It implies withdrawal from some things in order to deal effectively with others, and is a condition which has a real opposite in the confused, dazed, scatterbrained state which in French is called distraction, and Zerstreutheit in German. (James 1950: 403-404)

In general there are four main fields in which attention plays a more or less important role and where it is object of theoretical works: (1) Cognitive sciences and Psychology, (2) cultural studies and literature (Frank Kermode, Aleida and Jan Assmann), the field of (3) economics which is the most problematic field because it is not only rooted in economics but seems to be rather an interdisciplinary approach of psychological, sociological, philosophical and economic thinking within the paradigm of media culture and communication (Herbert Simon, Georg Franck, Michael Goldhaber, David N. Lanham). Finally attention appears in the discourse of (4) phenomenology which is, regarding the phenomenon of attention, represented primarily by Edmund Husserl, Paul Valéry and Bernhard Waldenfels in philosophy.

The 'Economy' or 'Economics of Attention' which will be the most important source for this article, is a discourse from the 90s that focused on the New Economy within new information technologies, especially the Internet, but above all it was accompanied by a whole analysis and diagnostic of the present time and society. Although the thesis, that money will be obsolete and replaced by an attention economy with attention as the new and dominant currency is more than doubtable, there are many interesting details and observations in the different visions that are represented by Michael H. Goldhaber, Georg Franck and Richard A. Lanham. According to Lanham for example, style is the means by which attention is attracted and allocated. The key to an economy of attention is the notion of information society. But why is it not called "information economy” then? As Michael Golhaber says:

By definition, economics is the study of how a society uses its scarce resources. And information is not scarce - especially on the Net, where it is not only abundant, but overflowing. We are drowning in information, yet constantly increasing our generation of it. So a key question arises: Is there something else that flows through cyberspace, something that is scarce and desirable? There is. (...) It is called attention. And the 
economy of attention - not information - is the natural economy of cyberspace. (Goldhaber 1997: 182)

The biggest problem in the approaches is that their theoretical argumentation and explanations are not always systematic or sufficient. However one can say that the architect and economist Georg Franck has got the most fertile and richest definition of attention. To him attention always means two different states: the intentional state of focussed attention and the more general state of awareness where background information is included. (Franck 1998: 28/29) In this conception Franck refers to Edmund Husserl who distinguishes between the intentional act of directing attention to s.th. and a certain background activity which comes very close to the state of a general alertness or awareness. Indeed, it is the German word Aufmerksamkeit which implies the two meanings of attention and awareness.

\section{Attention as Resource}

With respect to information management practices, the question is: how to deal with the flood of information and ideas? And how does attention as a mental resource bring structure and evaluation into this abundance of information in the personal and public awareness? As Herbert Simon points out a certain problem with information and news in 1983:

I suppose a society that became highly sensitive to the scarcity of attention might modify its reading habits to allocate attention more efficiently. Although in our own society complaints about the fold of information are common enough, there is little evidence of people deliberately designing strategies to protect themselves from transient and the evanescent. It seems a novel idea to many people that news need not to be ingested simply 'because it is there'. (Simon 1983: 94)

So this is the one task people have to cope with: they have to take care, to select and to decide, that means that attention has an exclusive character. If you decide to pay attention to something you cannot pay it to another thing at that time. To select and chose an option means to abandon other options at the same time, and the other task with respect to attention is its judgemental or evaluative character which Georg Franck calls the emotional quality of attention. This is for example the field of experimental psychologists who want to see "what effect they have on a person's ability to attend to and retain a message.” (Radford 2005: 55)

Why is that your attention switches when you hear your name mentioned in the other room, but it doesn't switch when the name mentioned is that of someone who you do not know? How does your personal interest in the subject matter of a message relate to your ability to focus and to attend to it? Do you attend more diligently to male or 
female voices? English or American accents? Messages with rational or emotional appeals? (Radford 2005: 55)

To summarise the universal aspect of attention, every action or communicative act is dyed with the process of paying or receiving attention. But besides the evaluative and the universal characteristics of attention, Goldhaber and Franck also agree with each other on an anthropological level where attention is a fundamental human desire and need. Even though Goldhaber doesn't really give any concrete definition of attention - the same is valuable for Richard A. Lanham - he argues that attention is a scarce resource and addresses a fundamental human desire which may occur in multiple forms:

To summarize, attention can ground an economy because it is fundamental human desire and is intrinsically, unavoidably scarce. It can be a rich and complex economy because attention comes in many forms: love, recognition, heeding, obedience, thoughtfulness, caring, praising, watching over, attending to one's desires, aiding, advising, critical appraisal, assistance in developing new skills, et cetera. (Goldhaber 1997: 184)

Goldhaber is indeed not very far away from the economist theory, because it is no other than the well known economist and nobel prize winner Herbert Simon who brings up the idea of scarce attention in an economic view:

Similarly, in an information-rich world the wealth of information means a dearth of something else: a scarcity of whatever it is that information consumes. What information consumes is rather obvious: it consumes the attention of its recipients. Hence a wealth of information creates a poverty of attention and a need to allocate that attention efficiently among the overabundance of information sources that might consume it. (Simon 1971: 40)

Within his theory of bounded rationality and therefore limited cognitive capacities, Herbert Simon mentions the poverty of attention and the need for an efficient allocation. According to his opinion that scarcity is a fundamental aspect of life, Simon thinks that the rationality is supposed to allocate all the resources as there are among others time, money, oil and attention. The comparison to money leads us to the next aspect, attention as medium.

\section{Attention as Medium and Economic Currency}

So the question is: What is a medium and what is its function for the perception and understanding of the world? In a general approach you can say that human beings use symbols and abstract figures in order to cope with the world's complexity. These abstract forms, figures and symbolic representations are generalisations and therefore help to structure 
and reduce the outer complexity. The process of transferring or exchanging symbols (and that means information in general) is called communication and language is considered as the most powerful and main symbolic system human beings have for communicating information and meaning. According to Talcott Parsons, unspecific symbolic communication media like money replace the individual exchange process by representing all that can be bought with it. So whenever you talk of a medium, you must admit the idea of exchange processes. This is what the authors of the attention economy reclaim as Goldhaber writes: "Each time someone focuses on anybody else, that can be thought of as a "transaction" in this new economy - a transaction that usually doesn't involve money.” (Goldhaber 1997: 184) So just like there are several symbolic communication media like money, power and truth, attention is reclaimed to be a medium and currency in the information age.

Let me ask further what attention specifically does and how it functions as a medium? According to the theory of Attention Economy (Franck 1998), it is attention that gives, builds and creates the value of cultural goods and persons - according to Georg Franck attention is not only working in the public sphere but there also is a kind of rudimentary economic system that allocates the amount of attention in personal and private life. He distinguishes between a micro-economic and macro-economic system of recognition. The idea is that the highly developed system of recognition in the public sphere which has turned into a form of mental capitalism since mass media has entered the entire scene, has its origin and natural perform in the system of recognition with regard to the social and personal identity in daily life.

In this reflection of the social value of each person in the whole of society, the idea of social exchange is now more than a metaphor. It is not through electric currents of attention that people communicate and exchange opinions, but through words and forms of appreciation and valuation. It is with by entering of the third person that the social value is turned into a market value - a theoretical element which is based on George Herbert Mead's generalised other. The fact that we not only earn attention by direct communicative acts but also by indirect acts ${ }^{\mathrm{i}}$ (when people talk about us) makes that you can talk of a veritable development of an attention market. Attention, according to Franck here, already works as a sort of currency so that we can speak of a commercialization of self-worth. The income and outcome of social appreciation or valuation defines the social value of each person that has to be seen in a whole system, that Franck calls a market of social prestige. According to this thinking the social status of each person is defined through the allocation of social valuation, a process in which the value-setting character as well as the judgemental quality of attention as a medium is shown at its best. 
Nevertheless and according to Franck, attention doesn't take the form of a real economic currency until the next level, when mass media enter the field of communication and social exchange, and when the valuation is more and more allocated by indirect forms. Whereas Jürgen Habermas defines power and money as the principal media in politics and economy, attention shall now be the primary medium in science, arts and mass media, thus in those fields that Habermas calls the public sphere or, in a more general perspective, the system of symbolic reproduction. (Habermas 1982: 209)

4. Attention Economy, Mental Capitalism and popularity as an economic value

If you look at the three big concepts on attention economy from Lanham, Goldhaber and Franck, you can find a lot of similarities and it will be a task in the future to analyse all three approaches regarding their capacity to form a scientific theory. Lanham for instance, knowing by the way that he is "not a real economist" (Lanham 2006, xi), distinguishes between stuff and non-stuff, substance and style, and emphasises that allocating attention is a matter of style:

The devices that regulate attention are stylistic devices. Attracting attention is what style is all about. If attention is now at the center of the economy rather than stuff, then so is style. It moves from the periphery to the center. Style and substance trade places. And so do real property and intellectual property. In an economy of stuff, the laws of property govern who owns stuff. In an attention economy, it is the laws of intellectual property that govern who gets attention. (Lanham 2006: xii)

Although it is not clear what is meant by 'laws of intellectual property', it is remarkable that, according to Lanham, the whole society is going to change in the economics of attention so that the new economists will not be found in the traditional economics departments, but rather people who work in "disciplines that study how attention is allocated.” (Lanham 2006: xii) For highlighting this thesis, Lanham describes art as attention structures, pointing out two different types of artists: Andy Warhol as an opportunist, seeking money and celebrity, and Christo on the other hand, a serious planner and artistic entrepreneur. Like Goldhaber, he focuses on the World Wide Web and on how the common economy will be replaced by a new attention economy based on the model of internet communities. The World Wide Web "thus combines the power of a free market, where individual gain leads to collective benefit, with the cooperative ownership of the cultural conversation.” (Lanham 2006: 13) 
As we have seen, Franck tries to develop a social theory within a theory of mass media where television, and not the internet, is still the primary medium and institution for allocating attention. Here he again shares with Goldhaber and Lanham the position that popularity, and therefore also style, has become a leading value for social valuation and personal identity. Popularity becomes a value in itself and functions as a real capital, and so Goldhaber speaks of a star system:

\begin{abstract}
Already today, no matter what you do, the money you receive is more and more likely to track the recognition that comes to you for doing what you do. If there is nothing very special about your work, no matter how hard you apply yourself you won't get noticed, and that increasingly means you won't get paid much either. This trend in recompense in the US has been documented in The Winner-Take-All Society, a book by economists Robert H. Frank and Philip J. Cook. The authors note that the star system we are accustomed to in sports, entertainment, and the arts has migrated to the professions. As a September 3, 1997, front-page headline in The Wall Street Journal announced, "CEOs are stars now." That's how they are paid, hired, utilized, and dismissed. They operate with their companies more as attention-getting motivators than bosses. The same goes for rainmaking legal partners, high-powered lobbyists, and academics. More and more they are treated as celebrities. (Goldhaber 1997: 186)
\end{abstract}

I think that the Attention Economy could be capable of mediating between the political economy school and the popular culture school because the attention economy emphasizes "the determination of media ownership on media structures” (McQuail 2005: 8) on the one hand and at the same time focuses "on the ideological tendencies in content” (McQuail 2005: 8) on the other hand. The attention economy shares with the culturalist perspective the position where "popularity (variously defined) became a criterion of merit and a guide to understanding” (McQuail 2005: 9) and furthermore, it tries to conceptualise the capitalistic mechanisms of popularity as an economic value. Then again the theory of attention can add to the political economic perspective in what way technology, economics and politics are more and more driven by the processes of attention without denying the very economic core of it and reducing it to the fact of a new media culture. The mere look at the fact and need for agenda setting in politics, economy, news, journalisms and science but also in culture in general, is sufficient to show how highly important the allocation of attention regarding topics and themes is. The latest discussions about Swine Influenza and Climate Change show the significant role of having power over public opinion by which economic, scientific and political procedures can be legitimated.

Georg Franck suggests four different forms of value for popular persons: prestige, being the less specific form, reputation, prominence and fame. The last three forms, which not only 
refer to persons but also to things, products and brands, follow a specific order and can be measured with the help of different rankings and representative, systematic opinion research. So we could say that we live in the age of Rankings and of opinion research where the market value of persons and products is measured constantly and systematically. Even science is not excluded from this. According to Franck, there is a special form of attention in science, the citation, which functions as means of payment and as counting unit to measure the value of the author at the same time: "The legally prescribed way of acquiring the licence to use somebody else's information as a means of production is citation. (...) Citation means to owe payment of a fee. The fee is charged by the transfer of some of the attention earned by the citing author over to the cited author.” (Franck 2002: 18)

The British literary critic Frank Kermode, in his thoughts about canonicity in literature and arts, describes the comment as the most important form of attention within the construction and conservation of canons and traditions. In the following paragraph, I want to have a look at Kermode's Forms of Attention where he presents the relation between comment and canonicity, and I will move on to the concept of Cultural Memory. So what I am going to do is to finally look for the cross points between the three discourses as there are economics of attention, cultural memory and phenomenology with regard to the function of attention. The notion of Cultural conversation will serve as the main idea for joining all of the three discourses.

5. Attention Economy and Cultural Memory: is it all cultural conversation?

In 2001, Aleida Assmann published a book entitled Aufmerksamkeiten (Attentions) and in it claimed that attention, as a form of appreciation and valuation, plays an important role on the strategical as well as on the transcendental level of human life and culture. She refers to Frank Kermode who searches for answers to the following question in his book Forms of attention: "By what means do we attribute value to works of art, and how do our valuations affect our ways of attending them?” (Kermode 1985: xiii) His answer points to the specific roles of interpretation, interpreters and comments, so that all processes of allocating and perpetuating attention result in having access to a kind of 'cultural conversation'. To be a part of a cannon or to be inside it reveals a magical side of attention which is very ancient at the same time: "To be inside the canon is to be protected from wear and tear, to be credited with indefinitely large numbers of possible internal relations and secrets, to be treated as a heterocosm, a 
miniature Torah. It is to acquire magical and occult properties that are in fact very ancient.” (Kermode 1985: 90)

Thus on the one hand, the struggle for access to canons and access to cultural memory is a political one for artists and authors, fighting for the power of interpretation and public value of their works of art. On the other hand, the interpreters are required to be alert and to be ambitious in their work of interpretation: "These interpreters are required to be vigilant and industrious, for to maintain a canonical work, to keep it in a condition of timeless modernity, is a never-ending and delicate business. That is why the canon, though not closed, is hard to get into. Applicants are often advised to apply to some other canon, say the 'postmodern' one.” (Kermode 1985: 90) Kermode mentions the traditional distinction between knowledge and opinion and takes the Bible as example for a canon that has been reformed and whose authority has been contested. But he sees the problem of theological canon:

Canons, which negate the distinction between knowledge and opinion, which are instruments of survival built to be time-proof, not reason-proof, are of course deconstructible; if people think there should not be such things, they may very well find the means to destroy them. Their defense cannot any longer be undertaken by central institutional power; they cannot any longer be compulsory, though it is hard to see how the normal operation of learned institutions, including recruitment, can manage without them. (Kermode 1985: 78)

By relying on Richard Rorty, Nietzsche and Feyerabend, Kermode gives up the idea of a clear distinction between knowledge and opinion and ends up in relativism. Accordingly, he thinks that the canonicity in the history of arts and literature has never been impermeable. Anyway, Kermode's conclusion is that such forms of attention - whether it is in the field of religion, literature or somewhere else - should continue to exist, even if they are all, in the end, dependents of opinion. (Kermode 1985: 91) According to this, canons are deconstructible on the one hand, but necessary and fundamental to institutional operations on the other hand. I want to offer two arguments here for why he is right: on the one hand, the bounded aspect of attention is very important in this process (not all the good pieces of art can be seen or recognized) and again the degree of popularity plays an important role in the selection of works (someone or something that does not attract attention at all will not be seen), so any selection can never be based exclusively on knowledge.

This is also valuable for philosophical theories, and maybe for the rest of science as well although science still holds on the distinction between knowledge and opinion much more than literature, art and partially philosophy. If you cannot read all the philosophical works of the whole history, you have to make choices and that's where the construction of different 
canons and traditions, for instance in philosophy, is a necessary way to structure the abundance of information and works. There are similar conditions for the present publications and that is why scientific authors have to respect some rules and conditions of practicability as it is called in the philosophy of science. On the one hand authors have to think of their colleagues bounded rationality and on the other hands they have to pay attention to the fact and power of tradition. Recognition and acceptance of a work or an idea can only be guaranteed if you connect with traditions and established ideas. And this is the point where the name and the degree of reputation play such an important role, whether it concerns the name of a person, university, research establishment or publishing company. ${ }^{\text {ii }}$ In this view, the Foucauldian thought of the author's death just seems like a utopian vision of how attention should be allocated with regard to the text. According to the idea of reputation in the scientific market, Georg Franck distinguishes between the attractive power and the scientific value of a theory as he writes:

A good deal of the difference between the attractive power and the scientific value of a theory can be explained by the fact that theories earn attention not only as capital goods, but also as consumer goods. Scientific communication is far from being the only market for scientific information. Rather, the science industry's final products are information exported to society, which in turn is financing this industry. The main export market is that of technology. However, scientific information is also imported by the entertainment industry. Moreover, the borderline between scientific publishing and entertainment is blurred. By making use of the leakage, one and the same product can be made to earn attention on both markets. (Franck 2002: 13)

If you apply this remark to the discourse of attention economy itself, it is very interesting to notice that even the authors consider their approach not only as a product for the scientific market. So Lanham at the end of his preface writes: "Certainly this procedure will not be respectable in the eyes of professional economists, or of the many other scholars whose fields I touch on, but it may be useful to the ordinary reader, in whose existence I continue to believe.” (Lanham 2006: xiv) I don't want to discuss whether this concept of ordinary reader is true or useful, it just shows that according to Lanham the scientific market is not the only market for scientific information and he, as being the author, is aware of not following all the rules that are required for the academic market. At the same time you cannot deny that there is a scientific value and content in his ideas. My questions here would be: how can the fact that you don't respect rules help you to get more attention? And again is it possible to move from the one market to the other when the amount of attention on one market is high enough? Another point that is interesting about Lanham's self-explanation is that he invites the imaginary reader to continue the conversation. To Lanham writing and reading a book is part 
of a conversation and it is not without meaning that each of its chapters is followed by "Background Conversations" in which Lanham describes some of the places he is coming from "and where you might go if you want to continue the conversation.” (Lanham 2006: xiv) Then in the first chapter, he claims that the capital of attention economy "lies in the cultural conversation”. (Lanham 2006: 9) Also, Frank Kermode emphasises the very simple fact of continuing a conversation with regard to canonical procedures:

In thinking about canonicity in the history of the arts and literature, we have at once to reflect that our canons have never been impermeable; that our defenses of them are always more provisional than a church's would be; that we therefore have the advantage of being able to preserve the modernity of our choices without surrendering the right to add to them, even to exclude members of them, not by means of difficult administrative procedures but simply by continuing a conversation. (Kermode 1985: 78/79)

Conversation here is defined and seen as the central process: it has to be talked about! It has to be interpreted! It has to be commented! Conversation, Interpretation and Commentary are the key words concerning traditional canons as well as short-term orders in the Attention Economy, simply because nothing can survive in the Cultural Memory without constant affirmation and confirmation: "Since we have no experience of a venerable text that ensures its own perpetuity, we may reasonably say that the medium in which it survives is commentary." (Kermode 1985: 36) Although one must say that "the success of interpretative argument as a means of conferring or endorsing value is, accordingly, not to be measured by the survival of the comment but by the survival of its object.” (Kermode 1985: 67) Maybe we can say that the "primary purpose" is indeed to provide the medium in which its object survives, but at least in philosophy, the tradition of comments - being a text genre - is very popular and seems quite autonomous whether its object is still read or not: "We may quarrel, but on the whole everybody knows what is being talked about, even when the tone and content of the remarks are surprising. That is to say, the work of preservation and defence is carried on by many voices cooperating, however unwillingly, to one end, and not by a central authority resisting its challengers.” (Kermode 1985: 79)

So we can say that the exchange of attention is a very important cultural technique by which "the primary objects of my own attention have to be brought to the attention of another generation” (Kermode 1985: 88). For a long-term conservation there is needed an institutional background for maintaining the attention to an object - for instance by a museum - and the border between short-term attention and long-term attention (which can be in form of canon) is in flux, so that an established and institutionalised order of long-term attention is never 
irreversible or undeconstructible. "But I agree with those who say that the idea of tradition has never been so weak as it now is, the sense of a literary past less strong; and I therefore respect, in the work of such writers as Gadamer and Jauss, the attempt to make historical consciousness a modern and acceptable idea.” (Kermode 1985: 88/89)

As William James writes in his Principles: “Dugald Stewart says: “The connection between attention and memory has been remarked by many authors.” (James 1950: 427) Although the psychological mechanisms of the individual, biological memory is not relevant in our context, there is a similar connection on the level of collective memory. The thesis is that attention can be considered as Medium in the dialectics of Memory (tradition) and Communication (dialogue), and it is right to say that Jan Assmann's forms of collective memory need attention as Aleida Assmann confirms in her later publication. The question now is: How are the concepts of Attention Economy and Cultural Memory connected? How is Jan Assmann's distinction between communicative and cultural memory to be understood in relation to the concept of attention economy? Do mass media represent the new historical consciousness; did they overtake the communicative memory? And does the difference between Attention Economy and Cultural Memory correspond to Kermode's difference between History and Canon? How are mass media affecting Cultural Memory and isn't television a new institution for perpetuating attention, also in long-term duration?

Certainly, there are different short-term canons and rankings in our present and daily life that more or less have a great influence and impact on our lives and communicative memories. So one has to confess that Kermodes distinction between Canon (works said with timeless meaning) and History (works that are interpreted in their historical context) is not complete and maybe it is right that Attention Economy focuses more on the short-term order of attention while the concept of Cultural Memory is meant to analyse the long-term traditions and values. ${ }^{\text {iii }}$ But it is not sure whether you can really separate the Cultural Memory from the new media, for instance from television as the primary institution of mass media. (Franck 1998) At least you have to admit that the canons and different long-term orders of Cultural Memory are already gone over into and being perpetuated in television and now everything that wants to survive in Cultural Memory has to establish itself in the complex and intransparent Bable of Attention Economy.

As Michael Goldhaber points out in a very general view "there are also many ways to capture attention: via your thoughts, inventions, self-revelations, expressions, performances, artistic creations, achievements, pleas, and arresting appearances.” Goldhaber 1997: 184) But the most important aspect is that it is talked about, that it is discussed and interpreted. So the 
decisive and essential question is: which type of conversation is used, within the big cultural conversation, by which attention is exchanged for preserving or perpetuating the status of an object or a person?

\section{Attention - an Economic or Phenomenological Approach}

Let me start with a last observation before I end with my final conclusions on this topic. There is an impressive parallel between Economics and Communication theory as they share similar theoretical presumptions and assumptions in a general perspective. While exploring the question 'what communication is', Gary P. Radford gives several characteristics of what communication studies are about. He mentions for example the expectation for practical outcomes, the idea of exchange by which he means the transmission theory, and the will to predict communicative acts. On a broader level this is exactly what some economists are doing: dealing with exchange models (exchange of money or other goods) and the will to predict choices and decisions as for instance in the rational choice models. Radford refers to Grossbergs “regime of communication” which Radford in his book "On the philosophy of communication” questions and contests with respect to its underlying idea of a transmission model.

The case of Attention Economy and Cultural Memory is similar: on the one hand they are inheriting the transmission view while on the other hand they are challenging it, because attention just doesn't fit in it just like money or other material goods that can be exchanged. So how to classify these approaches? Although they share the underlying main paradigms of interaction and exchange with the "regime of communication", their objectives reach beyond the linguistic turn, being not reduced to linguistic communication or communication through language.

So let me characterise on this background the difference between phenomenological and economic approach to attention: While Measurability of attention is given in the Economic model, attention is considered as a non-measurable object in phenomenology. In this sense, these two approaches are not only different forms of philosophical expression but their way of how to conceive attention as phenomenon is just unequal.

The future task of philosophy is: Attention as a phenomenon must be seen one the same level like philosophical notions as experience, perception and consciousness. The question which role attention in the process of experience, memory and perception plays, is posed by Edmund Husserl, Paul Valéry and Bernhard Waldenfels, but it needs to be continued. The 
phenomenological view is not reduced to the ideal of rationality and exchange: it shows rather in what ways the self depends on other mechanisms, selves and subjects. This relational interdependency is, according to Georg Franck, left out in the economic models, and that's why he tries to combine his economic approach with phenomenological elements. This again allows to turn it into a critical perspective in which the politics of recognition must be considered. A critical perspective on the Attention Economy must concern critics of acceleration, alienation and heteronomy.

The future task of economics is to find ambitious and enthusiastic economists who really work on integrating attention in a practicable economic theory. With this lecture I finally wanted to show that the concept of an Attention Economy is likely compatible with the idea of Collective Memory in cultural studies, so for creating a real theory of Economics of Attention, it would be necessary to work in the fields of philosophy, communication, cultural studies and economics.

\footnotetext{
${ }^{\mathrm{i}}$ „Erstens nehmen wir Aufmerksamkeit nicht nur durch direktes Einhandeln, sondern auch dadurch ein, dass Dritte über uns reden. Zweitens sind die Übergänge zwischen dem unvermittelten Naturalientausch und dem geldvermittelten Warentausch gleitend. Die Aufmerksamkeit, die zum Beispiel durch Reputation zufließt, wird fast ausschließlich auf indirektem Weg eingenommen. [...] Das Nebeneinander direkter und indirekter Formen des Tauschs war auch und gerade für die historische Herausbildung von Märkten charakteristisch. Wenn ein für allemal ausgeschlossen werden soll, dass der Tausch der Aufmerksamkeit eine ähnliche Entwicklung nimmt, dann muss sich zeigen lassen, dass der unterbundene Weitertausch auch jede Art mittelbarer Bewertung verhindert.“ (Franck 1998: 98)

ii، Science is not only the business of individual persons, but also of organizations. As a rule, individuals participate in the market of scientific information as members of a university or research establishment. (...) The organisation participates in the income earned by its members." (Franck 2002: 21)

iii This is what Aleida Assmann suggests as criterion to distinguish between print age and information age. (Assmann 2001: 13)
}

References

Assmann, Aleida (2001), Aufmerksamkeiten, Aleida und Jan Assmann (ed.), München: Fink. Franck, Georg (1998), Ökonomie der Aufmerksamkeit, München / Wien: Hanser. 
Franck, Georg (2002), 'The scientific economy of attention: A novel approach to the collective rationality of science', in Scientometrics : an international journal for all quantitative aspects of the science of science, communication in science and science policy, Budapest : Akadémiai Kiadó ; Dordrecht: Springer.

Goldhaber, Michael H.(1997), 'Attention Shoppers', in Wired, Boulder, Colo.: Condé Nast Publ., no. 5, pp. 182-191.

Habermas, Jürgen (1982), Theorie des kommunikativen Handelns, Vol. II, Frankfurt am Main: Suhrkamp.

James, William (1950), The Principles of Psychology, Vol. 1, New York: Dover Publications.

Kermode, Frank (1985), Forms of attention, Chicago [a.o.]: Univ. of Chicago Press.

Lanham, Richard A. (2006), The economics of attention: style and substance in the age of information, Univ. of Chicago Press.

McQuail, Denis (2005), 'Introduction and Overview', in Denis McQuail, Peter Golding, Els de Bens (eds.), Communication Theory \& Research. An EJC Anthology (European Journal of Communication), pp. 1-11.

Radford, Gary P. (2005), On the philosophy of communication, Belmont: Thomson Wadsworth.

Simon, Herbert (1983), Reasons in human affairs, Stanford University Press.

Simon, Herbert (1971), 'Designing organizations for an information-rich world', in Martin Greenberger (ed.), Computers, communications, and the public interest, Baltimore [a.o.]: Johns Hopkins P., pp. 37-72. 